\title{
Mechanism Analysis on Combined Toe-and-side Grouting for Cast-in-situ Piles
}

\author{
Peikang Zhou ${ }^{1, a^{*}}$, Jianfeng Liang ${ }^{1, b}$, Xinquan Wang ${ }^{2, c}$, \\ Yunliang Cui ${ }^{2, d}$ and Wenkai Qiao ${ }^{2, e}$ \\ ${ }^{1}$ Shaoxing Traffic Engineering Quality Safety Surveillance, Shaoxing, China \\ ${ }^{2}$ Zhejiang University City College, Hangzhou, China \\ a59452512@qq.com, b45872256@qq.com, cwangxq@zucc.edu.cn, \\ dcuiyl@zucc.edu.cn, ${ }^{\mathrm{e}} 1559916070 @ q q . c o m$
}

Keywords: Cast-in-situ Pile, Post-grouting, Bearing mechanism, Combined Toe-and-side Grouting

\begin{abstract}
Based on the construction technology of post-grouting, the load transfer mechanism, bearing capacity increasing mechanism and variation of pile-side and pile-toe resistance of combined toe-and-side grouted pile are analyzed. The mechanism of increasing of pile-side resistance and pile-tip resistance by post-grouting are discussed. It is believed that the increase of pile-side resistance by post-grouting relies largely on the improvement of pile-soil interface, improvement of mechanical property of pile-around soil and expanded-base effect of increased pile diameter. The increase of pile-tip resistance by pile-toe post-grouting mainly depends on improved mechanical property of pile-toe soil, change of pile-end destruction form, and expanded-base effect by increased pile-toe diameter.
\end{abstract}

\section{Introduction}

Since 1960s, cast-in-situ bored piles have been widely used in highway and railway bridge projects in China, due to the high quality, large bearing capacity, good stability, low cost, strong adaptability and convenient construction. However, the cast-in-situ piles using single technology often fail to meet the requirements on bearing capacity due to construction conditions or other facts. Post-grouting for cast-in-situ bored piles refers to injection of grout through pile-toe and pile-side grouting valves which are connected to grouting pipes preset in the pile shaft a certain time after forming of cast-in-situ piles. Chen Fei [1] have sketched that the pile-side and pile-toe post-grouting greatly increase single-pile bearing capacity of cast-in-situ bored piles, and analyzed the action of post-grouting on soil mass and pile shaft by using the pile-soil theory. An Jing [2] has proposed a practical formula for calculating post-grouting pile bearing capacity based on analysis on experimental data, and verified actual effects of post-grouting in typical projects, showing that post-grouting can greatly increase pile-toe resistance and pile-side frictional resistance. Xie Zhihao [3] has introduced application of post-grouting for cast-in-situ bored piles in engineering based on specific projects, and analyzed the experimental results, and suggested that the technology can significantly increase pile bearing capacity and reduce pile foundation settlement. Based on the results from static tests and pile shaft stress tests in cast-in-situ bored piles using post-grouting in soft soil, and taking into consideration of deformation caused by soil continuity, Huang Shenggen [4] have corrected the relationship between measured frictional resistance and displacement of pile sections, and obtained the ultimate frictional resistances of various pile sections by fitting frictional resistance and displacement is transfer function, so as to reflect the distribution rule of frictional resistance along the pile after grouting. Zhang Xiangming [5] have addressed the post-grouting construction technology in cast-in-situ bored piles, control parameters and its applicable strata, and analyzed the action and working mechanism. To sum up, although post-grouting in cast-in-situ piles has been applied in some projects, the study on the action mechanism remains incomplete and not deep. Moreover, current research is mainly focused on pile-toe grouting. Therefore, the mechanism for combined toe-side grouting requires further study. 


\section{Construction Process for Post-grouting}

The process flow for post-grouting construction is shown in Fig. 1.

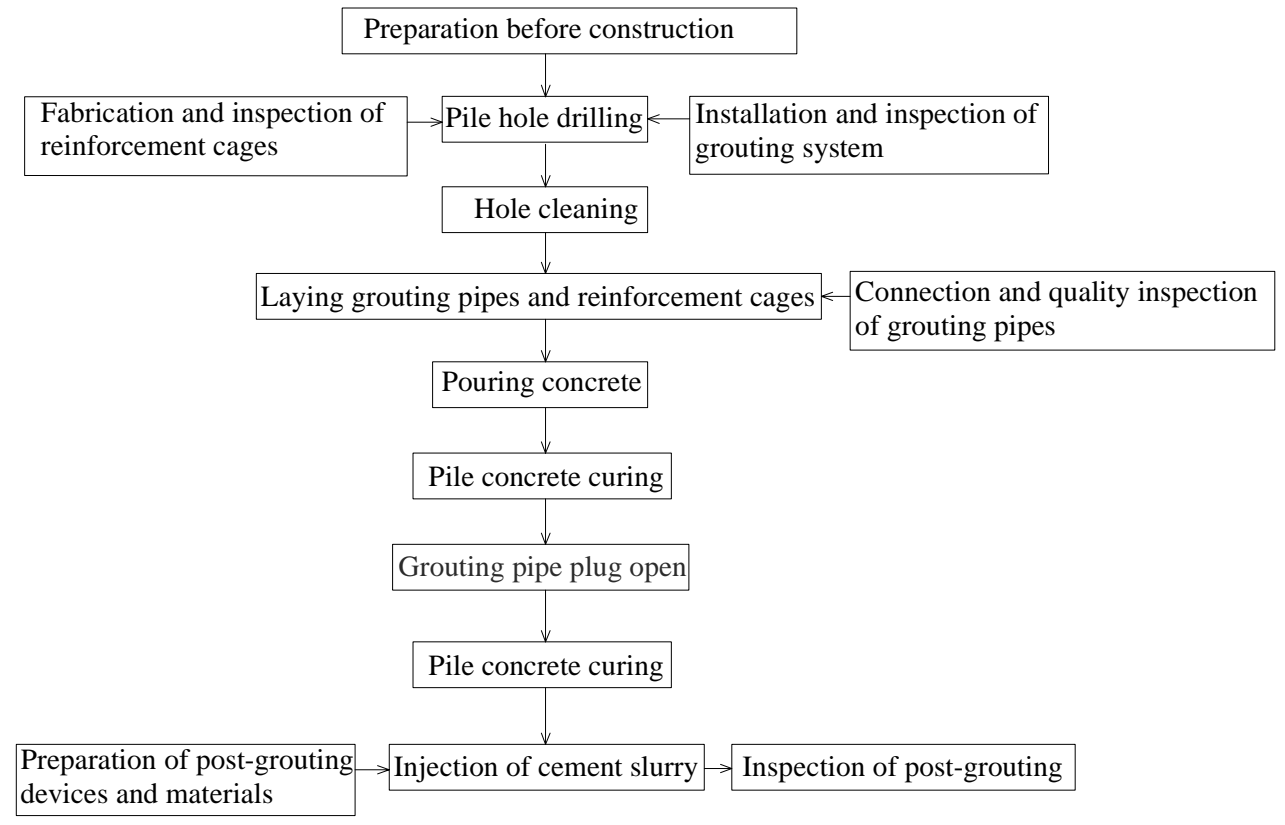

Fig. 1 Construction process for post-grouting.

\section{Bearing Mechanism for Post-grouting}

The bearing capacity of the cast-in-situ bored pile consists of pile-toe resistance and pile-side frictional resistance. In general design, due to the safety factor, under working load, most of frictional resistance has been given play to, as well as only a fraction of pile-toe resistance. The exerting degree of frictional resistance depends on the magnitude of top load. The pile-side frictional resistance comes into play from the top down in an asynchronous way. And the pile-side frictional resistance and pile-toe resistance also come into play in an asynchronous way. The pile-toe resistance only comes into play when the force of the pile shaft transfers to and press the soil under the bottom. When the relative displacement of the soil at a certain section reaches its displacement limit, the soil layer will slip relatively, and the side frictional resistance after that is the ultimate frictional resistance.

\section{Mechanism Analysis for Improving Pile Bearing Capacity by Post-grouting}

The mechanism of action for post-grouting in cast-in-situ bored piles is to improve pile-soil interface, reinforce pile-side and pile-toe soil, and reduce adverse effect of mud cake and sediment through penetration, compaction and separation of grout in rock and soil mass, so as to facilitate the action of pile-side frictional resistance and pile-toe resistance and increase pile bearing capacity. For the adaptability and post-grouting selection of soil layers, the soil layer with loose structure or well-developed fissure and that of coarse grain have a good improvement or grouting effect, compared with soil layers of fine grain. The order of priority for the quaternary stratums according to loose structure and porous development are as follows: gravel, sand and gravel, medium-coarse sand, fine sand, silt and clay. For non-socketed piles, the pile-toe bearing layer, the pile-toe grouting layer, should be medium density or dense gravel layer as far as possible; if both pile-toe grouting and pile-side grouting are applied, the toe grouting layer and side grouting layer should be spaced by at least $15 \mathrm{~m}$, to avoid permeation and diffusion being affected. For socketed piles, the pie-toe bearing layer usually is located at a slightly weathered stratum, and the embedded depth should not be less than one time the pile diameter.

Mechanism by which Post-grouting Increases Pile-side Frictional Resistance. Post-grouting 
effectively reinforces the soil around and improves its mechanical property, so its ability to transfer shearing strength and side frictional resistance are increased. In addition, post-grouting cements, compacts and reinforces the soft mud cake around the pile, so as to eliminate the weak layer and improve mechanical property of pile-soil interface, which will help the exertion of side frictional resistance. The filling and compaction of grouting in soil forms a cement-consolidated body around the pile, and effectively reinforces the soil, changing the pile-soil destruction location from the junction between the pile and pile-side weak layer to that between the reinforced zone to the soil around the pile. It means that the pile diameter is increased, and the peripheral surface area is effectively increased, so the total side frictional resistance $Q_{s}$ is increased.

Decrease Bottom Sediment Thickness and Reinforce Bottom Bearing Layer. Regardless of the nature of bottom soil, the grout solidifies with the bottom sediment, to form a consolidated body of high strength and stable in chemistry, to reduce sediment thickness. Meanwhile, the grout diffuses and penetrates through the pores in the pile-toe bearing layer, remarkably increasing the bottom soil strength and pile-toe resistance, and the compression deformation at pile toe is partly completed in construction period, which reduces vertical compression deformation in later use.

Improve Pile-soil Interface Characteristics. During pile-toe grouting, along with the increase in grouting volume and grouting pressure, the grout will penetrate along the mud cake around the pile in a certain height above the pile toe, to reinforce the mud cake, fill the gap between the pile shaft and around soil, and penetrate into a certain width in the around soil. The consolidation of grout makes the soil around the pile in a larger range to contribute to the bearing capacity of the pile, and improve pile-soil interface.

Compaction of Pile Shaft Concrete. When pile-toe and pile-side grouting is performed, the concrete of pile shaft has not been solidified completely and will be compacted further in the grouting process, and some bubbles formed in pouring concrete will be removed, so the compressive strength and elastic modulus of the pile shaft concrete will be increased.

\section{Variation of Pile-side and Pile-toe Resistances}

When the load is relatively low, the load transfers along the pile downward, but does not reach the bottom. All the load is borne by the side frictional resistance, and the side frictional resistance of the upper around soil comes into play firstly and then that of lower part. Since the ultimate displacement at pile toe is much larger than that at pile side, during the exertion of side frictional resistance, the pressure to the pile-bottom soil is small. The distribution of side frictional resistance is associated with pile soil friction characteristics. When the load increases, the deformation of pile-bottom soil increases and the piriform area formed expands upward, increasing the pressure in the radial direction near the pile toe and ultimate side frictional resistance.

The interaction between pile-side frictional resistance and pile-toe resistance always exist, but will emerge when the pile-toe load increases to a certain magnitude. And the increase in side resistance by pile-toe resistance is only significant near the pile toe, and the range affected is related to the nature of the pile-toe soil. Compared with the increase in pile-side frictional resistance by pile-toe resistance, the increase in pile-toe resistance by side resistance is not significant.

\section{Conclusion}

(1) Post-grouting for cast-in-situ bored piles greatly increase single-pile ultimate bearing capacity, owing to the filling, cementation, solidification and reinforcement effects by grout in pile-toe and pile-side soil.

(2) Post-grouting increases pile-side frictional resistance through three actions: improvement of pile-soil interface, improvement of mechanical property of pile-around soil and expanded-base effect of increased pile diameter.

(3) The pile-toe post-grouting increase the end resistance through three actions: improvement of mechanical property of bottom soil; change of pile-toe destruction form from pricking destruction to local shearing destruction; and expanded-base effect by increased pile-toe diameter. 
(4) For post-grouting in cast-in-situ piles, the pile-side frictional resistance interacts with pile-toe resistance; compared with the increase in pile-side frictional resistance by pile-toe resistance, the increase in pile-toe resistance by side resistance is not significant.

\section{Acknowledgement}

This work is funded by Zhejiang Provincial Communication Department Scientific Research Plan Project (2014H34) and Zhejiang provincial Educational Scientific Research Project (Y201533738).

\section{References}

[1] F. Chen, K. Lan, Mechanism and application of post pressure grouting of bored Pile. Geologic.

Sci. Technol. Inform. 24(z1) (2005) 97-100.

[2] J. An, Mechanism and bearing characteristics analysis on post-pressing mortar of hole-digging grouting pile, Shanxi Archit. 36(5) (2010) 133-134.

[3] Z. H. Xie, Application \& effectivity of post-pressing mortar technology of hole-digging grouting pile. Shanxi Archit. 31(13) (2005) 58-59.

[4] S. G. Huang, X. W. Zhang, H. Cao, Mechanism study on bored cast-in-place piles with post-grouting technology. Rock Soil Mech. 25(2) (2004) 251-254.

[5] X. M. Zhang, J. P. Chen, After drill hole filling pile mud jacking construction technology and application effect analysis. China Water Transport. 7(5) (2007) 82-85. 